\title{
Ações de uma Empresa Júnior em Fonoaudiologia Voltadas à Comunidade Coralística
}

\section{Actions of a Junior Company in Speech, Language and Hearing Sciences Aimed at the Choral Community}

\author{
Carla Regina Chaves Henriques ${ }^{1}$, Matheus Francoy Alpes ${ }^{2 *}$, Gabriela Lima Ricci ${ }^{3}$ e Aline \\ Epiphanio Wolf ${ }^{4}$ \\ ${ }^{1}$ Fonoaudióloga pela Faculdade de Medicina de Ribeirão Preto da Universidade de São Paulo \\ ²Fonoaudiólogo pela Faculdade de Medicina de Ribeirão Preto e Doutorando do Programa de Pós-Graduação \\ em Clínica Médica da Faculdade de Medicina de Ribeirão Preto da Universidade de São Paulo \\ ${ }^{3}$ Fonoaudióloga pela Faculdade de Medicina de Ribeirão Preto e Mestre em Ciências Médicas pela Faculdade de \\ Medicina de Ribeirão Preto da Universidade de São Paulo \\ ${ }^{4}$ Docente do Curso de Fonoaudiologia da Faculdade de Medicina de Ribeirão Preto da Universidade de São Paulo
}

* Autor para correspondência: matheus.alpes@usp.br

\begin{abstract}
RESUMO
A Empresa Júnior tem o objetivo de proporcionar aos alunos a possibilidade de colocar em prática os conteúdos teóricos aprendidos durante a graduação e difundir os conhecimentos e possibilidades de atuação para seu públicoalvo. A Empresa Júnior em Fonoaudiologia da FMRP-USP foi fundada em 2011, e as ações fonoaudiológicas voltadas à comunidade coralística abordadas neste relato foram realizadas em 2013. Como ação, foi ministrada uma palestra informativa sobre higiene vocal, fisiologia e anatomia das estruturas para a produção vocal e o uso da voz, e a avaliação e a orientação fonoaudiológica específica eram disponibilizadas aos integrantes do coral interessados, posteriormente. A Empresa desenvolve projetos de diversas temáticas até os dias atuais e tem evidenciado constante crescimento e reconhecimento dentro e fora do campus.
\end{abstract}

Palavras-Chave: Extensão Comunitária; Organização; Fonoaudiologia.

\begin{abstract}
The aim of the Junior Company is to provide students with the possibility of putting into practice the theoretical contents learned during undergraduation and to disseminate the knowledge and possibilities of action to their target audience. The Junior Company in Speech, Language and Hearing Sciences of Medical School in University of São Paulo was founded in 2011 and the speech-language pathology actions addressed to this choral community were carried in 2013. As an action, an informative lecture on vocal hygiene, physiology and anatomy of structures for vocal production and voice use, and specific speech-language assessment and guidance were made available to interested choral members. The Company develops projects of various themes up to the present day and has shown constant growth and recognition inside and outside the campus.
\end{abstract}

Keywords: Community-Institutional Relations; Organization; Speech; Language and Hearing Sciences.

\section{Introdução}

A ideia de "Empresa Júnior" foi iniciada no ano de 1967 na Universidade Superior de Ciências Econômicas e Comerciais, em Paris, França, com o objetivo de proporcionar aos graduandos a possibilidade de colocar em prática os conteúdos aprendidos teoricamente (MATOS, 1997). Nos anos posteriores, já existiam no país mais de cem empresas juniores, e posteriormente houve uma disseminação por todo o continente europeu, culminando em 1990 na criação da Junior Association for Development in Europe - JADE (BRITTO, 2008).

No Brasil, no final da década dos anos 1980, três cursos de universidades brasileiras criaram 
empresas juniores: Fundação Getúlio Vargas (FGV), Fundação Armando Alvares Penteado (FAAP) e a Escola Politécnica da Universidade de São Paulo (USP), após contato com a Câmara de Comércio França-Brasil (OLIVEIRA, 2004).

O surgimento dessas empresas no Brasil estava diretamente relacionado com o momento político e social do país, em que havia uma transição para a redemocratização depois de vinte anos de Ditadura Militar e a busca por possibilidades de abertura política, que foram consolidadas na Constituição de 1988. Em relação à educação superior, começou-se a instituir atividades voltadas à extensão e à criação de vínculos na díade universidade-comunidade, favorecendo a proposição de que a Empresa Júnior seria um espaço importante de ensino, extensão e pesquisa em instituições de nível superior (RAFAEL \& OLIVEIRA, 2012).

Atualmente, há o funcionamento de Empresas Juniores associadas às instituições superiores de ensino, públicas e privadas em todo o território nacional, voltadas a diversas áreas e em diferentes vertentes, buscando o oferecimento de serviços ao seu público-alvo (SPAGNOF \& BASTOS, 2013). Na área da saúde, há organizações voltadas à Medicina, Psicologia e Enfermagem com estudos publicados acerca de sua fundamentação e ações realizadas em seu âmbito de inserção (TERRIM, MELO \& JÁCOMO, 2015; SPAGNOF \& BASTOS, 2013; PERES, CARVALHO \& ASHIMOTO, 2004). Entretanto, na Fonoaudiologia, sabe-se que há Empresas nas regiões Sudeste e Nordeste do Brasil, mas até o momento não foram encontradas publicações científicas referentes a estas.

O profissional fonoaudiólogo é responsável pela avaliação, diagnóstico e (re)habilitação de aspectos inerentes à comunicação humana, e a voz, instrumento fundamental para que ocorra esse processo, é comumente utilizada como objeto de estudo dessa ciência. A voz pode ser utilizada de forma falada ou cantada, e a abordagem clínica, terapêutica e informativa aplicada difere a cada uma delas.
O coral, exemplo de utilização da voz cantada, é composto por indivíduos dotados de vozes com diferentes características vocais e acústicas, buscando a harmonização de todos para resultar em uma boa sonoridade grupal (AMATO, 2007). Sendo assim, além da participação do regente e do cantor, torna-se fundamental a atuação do fonoaudiólogo para realizar um trabalho de educação e preparação vocal dos cantores, para que com isso possam cumprir com as exigências que essa modalidade musical requer, sem prejudicar suas próprias vozes e o resultado sonoro final do grupo (BEHLAU \& REHDER, 2008).

Os aspectos coralísticos apresentam particularidades que os diferenciam de outras modalidades da voz cantada, e alguns parâmetros vocais devem ser considerados. A maioria dos corais, formados em igrejas, comunidades, escolas, faculdades e clubes, é composta por cantores amadores, que não possuem conhecimento acerca de alguns processos internos do próprio organismo necessários para a sua realização, como a respiração, a projeção e a tessitura vocal (LOIOLA \& FERREIRA, 2010), e muitas vezes acabam apresentando queixas referentes a possíveis inadaptações e/ou dificuldades, como dor, fadiga vocal, lesões, afonia, entre outros.

Cada grupo possui suas capacidades, limitações, necessidades e especificidades em relação à saúde vocal, e conhecer os problemas enfrentados por cada um auxilia no planejamento das ações a serem instauradas. Nos dias de hoje, já existe um maior conhecimento de que o fonoaudiólogo é o profissional responsável por repassar orientações sobre saúde vocal aos profissionais da voz e promover tratamento adequado, quando necessário (UEDA, SANTOS \& OLIVEIRA, 2008).

Entretanto, ainda existe um longo caminho pela frente quanto à divulgação, e o conhecimento acerca da atuação dos profissionais da Fonoaudiologia e a instauração de Empresas Juniores na área podem vir a auxiliar nesse processo, inserindo graduandos do curso em atividades de pesquisa, ensino e extensão universitária, difundindo conhecimentos e estabelecendo contatos com possíveis clientes. 
Assim, o objetivo deste estudo é descrever ações realizadas por uma Empresa Júnior em Fonoaudiologia de uma Universidade pública no interior de São Paulo à comunidade coralística da cidade de Ribeirão Preto, São Paulo.

\section{Métodos}

Pesquisa retrospectiva e descritiva, com o relato de ações realizadas por uma Empresa Júnior em Fonoaudiologia de uma Universidade Pública do interior de São Paulo, acerca de ações voltadas à comunidade coralística.

\section{Resultados e Discussão}

Através da experiência e do apoio da docente colaboradora e da iniciativa da gestão do ano de 2013, foi elencada a ideia de realização de um projeto voltado à comunidade coralística na cidade de Ribeirão Preto, São Paulo.

A equipe gestora foi dividida para proceder a um levantamento dos corais da cidade, separado por áreas. Esses corais não eram necessariamente de profissionais, mas sim de iniciativas menores, como corais de igrejas, hospitais e outras organizações não formais.

Analisando tal demanda, e vendo a possibilidade de um serviço em que a Fonoaudiologia poderia intervir, elaborou-se um projeto de atuação. Em discussão com a gestão em vigor, foram estabelecidas algumas ideias e formas de apresentação para atrair o público-alvo. O fonoaudiólogo atuaria na comunidade coralística, realizando avaliação vocal específica de cada integrante, ministrando exercícios de aquecimento vocal associados a noções de anatomia e fisiologia da voz aplicada ao canto, discussões sobre saúde vocal, treino com respiração e propriocepção da voz (RIBEIRO et al., 2012; LOIOLA \& FERREIRA, 2010).

Foi estabelecido um contato prévio com os corais levantados para a exposição do projeto, que contava com uma justificativa e apresentação do serviço, a partir de uma base literária e científica, como de praxe em projetos, para que assim o consumidor final tivesse uma base sólida para entender a necessidade e a importância de sua realização. Continha ainda a apresentação detalhada de toda a proposta de avaliação vocal dos participantes, com uma anamnese vocal, com o Questionário de Qualidade de Vida em Voz - QVV (GASPARINI \& BEHLAU, 2009), avaliação acústica através do programa de computador Vox Metria - Análise de Voz $e$ Qualidade Vocal e a avaliação perceptivo auditiva (com inclusão de gravação vocal para posterior análise). Havia ainda a documentação de que as amostras seriam discutidas com a docente responsável e seria entregue uma devolutiva escrita dos parâmetros analisados e orientações individuais.

Os instrumentos utilizados foram escolhidos como forma de atender e entender as possíveis queixas vocais por parte dos coralistas, realizar avaliação acústica para identificar possíveis patologias passíveis de investigação a partir de avaliação vocal, e ainda havia a pretensão de devolver uma perspectiva ao regente do coral em relação a quanto a voz de cada coralista poderia ser estimulada, em relação às notas que o paciente estaria confortável em atingir.

Para os corais que atenderam e aderiram à oferta, foi então realizado o seguinte procedimento. Inicialmente era feita uma apresentação oral da docente colaboradora e dos integrantes da Empresa para todos os coralistas participantes, com noções de higiene vocal, anatomia e fisiologia das estruturas envolvidas para a produção vocal, uso da voz, e sanadas dúvidas quanto ao assunto de maneira global. Após essa apresentação, os coralistas conheciam a proposta de avaliação acima descrita.

Essa estratégia foi utilizada, pois os corais normalmente não contavam com uma verba para contratação do serviço, mesmo se mostrando interessados no fechamento do mesmo. O serviço então era contratado de forma terceirizada: os coralistas que se mostravam interessados pelo serviço pagavam sua contratação à parte para o coral, que posteriormente entrava em contato com a Empresa para passar o número exato de pessoas interessadas. A apresentação da docente responsável antes do oferecimento do serviço era 
realizada sem custo, como uma ação de extensão e divulgação do conhecimento científico e da atuação fonoaudiológica e com a apresentação atrativa para a posterior contratação do serviço de avaliação.

Procedeu-se a um levantamento com profissionais formados e atuantes na área, sobre valores e dinâmicas desse tipo de oferta. Os serviços prestados eram cobrados com um preço abaixo do valor de mercado, visto a ideia de ser oferecido por uma Empresa Júnior composta por graduandos em formação, supervisionados por uma docente.

Um estudo realizado com a comunidade coralística constatou que a proposta de intervenção fonoaudiológica com cantores de coral amador gerou efeitos positivos nos parâmetros de respiração, projeção e tessitura vocal em contexto de voz cantada, além de que, na autoavaliação, todos os cantores fizeram referência à melhora nos três parâmetros avaliados (LOIOLA \& FERREIRA, 2010). Um outro estudo feito no Brasil verificou que, após um ano de intervenção fonoaudiológica, a prática do canto coral trouxe benefícios vocais aos sujeitos por meio do desenvolvimento e aprimoramento individual da emissão vocal (VIEIRA, GALDENZ \& CASSOL, 2015).

Até hoje, a Empresa Júnior em Fonoaudiologia da Faculdade de Medicina de Ribeirão Preto encontra-se em vigor, desenvolvendo projetos em diversas áreas de atuação fonoaudiológica, participando e ministrando cursos de capacitação e de extensão e têm demonstrado crescimento considerável dentro e fora do campus.

Sabe-se que é de extrema importância a participação de graduandos em atividades extracurriculares, em especial em empresas juniores, sendo este um fator decisivo para estimular o empreendedorismo e a inovação na vida profissional posterior (TERRIM, MELO \& JÁCOMO, 2015). Uma pesquisa que comparou alunos participantes e não participantes de empresas juniores constatou que estes apresentavam maior senso de iniciativa, propensão a riscos, necessidade de realização, criatividade, motivação e flexibilidade, em comparação com o grupo controle, além de possuir maior entendimento sobre o papel do empreendedorismo na sociedade (GIBCUS et al., 2012).

\section{Conclusões}

A Empresa Júnior em Fonoaudiologia da Faculdade de Medicina de Ribeirão Preto da Universidade de São Paulo foi fundada em 2011 e, desde então, vem realizando ações de atuação fonoaudiológica em diversas vertentes.

No ano de 2012, a ação com a comunidade coralística da cidade consistiu na realização de uma palestra informativa com a docente apoiadora e os integrantes da Empresa, acerca de noções de higiene vocal, anatomia e fisiologia das estruturas envolvidas para a produção vocal e o uso da voz. Posteriormente foram oferecidas aos participantes do coral a avaliação e a orientação fonoaudiológica específica e individual.

O projeto foi realizado até o ano de 2014, entretanto a Empresa desenvolve projetos variados, participa e ministra cursos de capacitação e de extensão e tem demonstrado crescimento e reconhecimento dentro e fora do campus universitário.

\section{Referências Bibliográficas}

AMATO, R. F. "O Canto Coral como Prática Sociocultural e Educativo-Musical". Opus Goiânia, Goiás, vol. 1, n. 13, pp. 75-96, 2007.

BEHLAU, M. \& REHDER, M. I. "Higiene Vocal para o Canto Coral". Revinter, Rio de Janeiro, vol. 1, 2008.

BRITTO, M. "Celeiros de Talentos". Empreendedor, [S.1.], n. 160, 2008, pp. 18-25.

GASPARINI, G. \& BEHLAU, M. "Quality of life: Validation of the Brazilian Version of the Voice-Related Quality of Life (V-RQOL) Measure". J Vice, [S.l.], vol. 1, n. 23, 2009, pp. 76-81.

GIBCUS, P.; KOK, J; SNIJDERS, J; SMIT, L \& LINDEN, B. "Effects and Impact of Entrepreneurship Programmes in Higher Education". Entrepeneurship Unit, Brussels, 2012. Disponível em: \http:// ec.europa.eu/enterprise/newsroom/cf/itemdetail.cfm?item_id=5894>.

LOIOLA, C. M. \& FERREIRA, L. P. "Coral Amador: Efeitos de uma Proposta de Intervenção Fonoaudiológica". Rev. Cefac., São Paulo, vol. 12, n. 5, Sept./Oct. 2010, Epub Apr 23, 2010.

MATOS, F. A Empresa fúnior no Brasil e no Mundo. São Paulo: Martin Claret, 1997. 
OLIVEIRA, E. M. Empreendedorismo Social no Brasil: Fundamentos e Estratégias. Tese (Doutorado em História, Direito e Serviço Social), Universidade Estadual Paulista, Franca, São Paulo, 2004.

PERES, R. S.; CARVALHO, A. M. R. \& HASHIMOTO, F. "Empresa Júnior: Integrando Teorias e Práticas em Psicologia”. Rev. Psicol., Florianópolis, vol. 4, n. 2, dez. 2004

RAFAEL, S. S. \& OLIVEIRA, L. R. "Empresa Júnior: uma Cultura Empreendedora Capaz de Fortalecer o Elo Entre Universidade e Comunidade". Revista Fluminense de Extensão Universitária, Vassouras, vol. 2, n. 1, jan.jun. 2012, pp. 61-70.

RIBEIRO, V. V.; SANTOS, A. B.; BONKI, E.; PRESTES, T. \& DASSIE-LEITE, A. P. "Identificação de Problemas Vocais Enfrentados por Cantores de Igreja". Rev. Cefac., [S.1.], vol. 1, n. 14, 2012, pp. 90-96.
SPAGNOF, C.A; BASTOS, J.M. "Empresa Júnior: Espaço Criativo e Empreendedor de EnsinoAprendizagem na Enfermagem". Enfermagem em Foco, [S.l.], vol. 4, n. 3, 4, 2013, pp. 164-166.

TERRIM, S.; MELO, A. A. R. \& JÁCOMO, A. L. "Empreendedorismo em saúde: relato de um modelo de Empresa Júnior em Medicina". Rev Med., São Paulo, vol. 2, n. 94, 2015, pp. 94-98.

UEDA, K. H.; SANTOS, L. Z. \& OLIVEIRA, I. B. "Vinte e Cinco Anos de Cuidados com a Voz Profissional: Avaliando Ações". Rev. Cefac., [S.l.], vol. 4, n. 10, 2008, pp. 557-65.

VIEIRA, R. H.; GADENZ, C. D. \& CASSOL, M. "Estudo Longitudinal de Caracterização Vocal em Canto Coral". Rev. Cefac., vol. 17, n. 6, 2015, pp. 1781-1791.

Publicado em 28/07/2020. 